\title{
Dinámicas sectoriales y desarrollo territorial en economías locales interiores. El caso de Rivera en Uruguay
}

\section{Sectoral dynamics and territorial development in interior local economies. The case of Rivera in Uruguay}

Adrián RodrígueZ-MirandA*

\begin{abstract}
From a local economic development approach this paper proposes a simple analytical model to characterize local interior economies based on two dimensions: sectoral innovation and local economic interrelationships. The model is applied to the case of Rivera in Uruguay in order to identify the different sectoral dynamics and their contribution to local economic development. Finally, we discuss the main results and some general conclusions are made on the application of the model.
\end{abstract}

Keywords: local economic development, economic sectors, innovation, productive organization, Rivera (Uruguay).

\section{Resumen}

El artículo propone un modelo de análisis sencillo para caracterizar economías locales interiores desde un enfoque de desarrollo económico territorial en función de dos dimensiones: la capacidad de innovación sectorial y las interrelaciones entre los sectores de la economía local. El análisis se aplica al caso de Rivera, en Uruguay, y a partir de él se realizan algunas consideraciones sobre los principales resultados encontrados y algunas conclusiones generales sobre el modelo aplicado. En particular, se discute sobre las dinámicas económicas sectoriales en este tipo de economía local y su contribución al desarrollo territorial.

Palabras clave: desarrollo económico local, sectores productivos, innovación, organización productiva, Rivera (Uruguay).

* Instituto de Economía de la Facultad de Ciencias Económicas y Administración de la Universidad de la República, Uruguay. Correo-e: adrianrm@iecon.ccee.edu.uy 


\section{Introducción}

En este trabajo se propone un modelo de análisis, desde un enfoque de desarrollo económico territorial, para caracterizar economías locales interiores en función de dos dimensiones: la capacidad de innovación de los sectores de la economía con potencial de transformación del sistema productivo local y las interrelaciones económicas entre estos sectores, y la economía local. Dicho enfoque se aplica al caso de Rivera, una economía interior del Uruguay.

El artículo presenta el marco conceptual desde una perspectiva territorial y endógena del desarrollo. En ese marco se discute la especificidad de las economías locales interiores, alejadas de las economías de aglomeración urbana y los principales centros de producción y consumo, así como las implicaciones en términos de cómo considerar el análisis de la innovación y las relaciones económicas locales en dichos contextos.

Para analizar el caso de Rivera el trabajo presenta un modelo de análisis que utiliza indicadores sencillos los cuales pueden ser construidos en contextos de poca información estadística oficial, recurriendo a un relevamiento propio de campo de relativamente fácil implementación y apoyándose en la información de carácter más general que sí puede estar disponible, como el peso en la economía local (por ejemplo, aproximado por el empleo) de los diferentes sectores y algunas de sus características básicas.

A partir del estudio de caso se realizan algunas consideraciones sobre los principales resultados encontrados y algunas conclusiones generales sobre el modelo de análisis aplicado. En particular, se analizan las dinámicas económicas sectoriales y su contribución al desarrollo territorial, dejando en evidencia que no siempre un gran emprendimiento o un desarrollo sectorial competitivo tienen correlato en el desarrollo de relaciones económicas locales que, a su vez, permitan el desarrollo del resto de la economía del territorio.

\section{Un marco conceptual de análisis para economías locales interiores}

\subsection{Una perspectiva territorial y endógena del desarrollo}

El presente trabajo parte de un marco teórico general que se puede denominar desarrollo económico territorial endógeno. Según este enfoque, el desarrollo económico de un territorio (regiones, localidades, ciudades) refiere un proceso endógeno de cambio estructural y acumulación de capital que se explica desde una visión territorial y no funcional (VázquezBarquero, 2002a, 2005), se entiende al territorio como un espacio de 
interacción entre actores, instituciones, capacidades, tradición y conocimientos (Rodríguez-Miranda, 2006).

La visión territorial difiere de una funcional en que no sólo se trata de analizar el desarrollo económico a partir de los recursos disponibles (trabajo, capital, recursos naturales) y los procesos de innovación y economías externas que se aplican a estos recursos, sino que esos procesos, en sí mismos, están afectados y son condicionantes y condicionados por la organización económica, social e institucional del territorio. Se trata de una visión del desarrollo que entiende a la economía como relaciones.

Como señala Storper (1988), los agentes son actores humanos reflexivos, tanto en forma individual como colectiva, por lo que el proceso económico implica también un proceso de coordinación; por lo tanto, la acumulación no refiere sólo a bienes y beneficios materiales sino también a activos relacionales.

A partir de estas consideraciones, puede ocurrir en un territorio un proceso de crecimiento económico (acumulación de capital y generación de excedente) pero no implicar necesariamente un proceso de desarrollo territorial. Por ejemplo, puede darse el caso de que ocurra un proceso de crecimiento económico para el que los agentes económicos y sociales locales no sean relevantes desde el punto de vista de la generación de competitividad y ventajas específicas para las actividades que allí ocurren, lo que se refleja seguramente en una escasa apropiación local del excedente generado.

Esto seguramente tendrá un correlato en una baja interrelación entre los actores económicos y organizaciones locales con esos sectores dinámicos que podríamos denominar como sectores que funcionan y crecen en forma exógena al territorio. En los casos más extremos el territorio opera apenas como una plataforma física de localización para ciertas actividades sectoriales, localización que responde a la presencia de un recurso natural abundante, una posición geográfica estratégica (distancias a las materias primas y los mercados finales tales que minimizan los costos de transporte) o el aprovechamiento de un régimen fiscal especial (subsidio). En consecuencia, puede existir desarrollo sectorial en un determinado recorte geográfico del territorio sin que exista desarrollo local (o regional).

El diferencial de la perspectiva territorial no está solo en la endogeneidad del proceso de desarrollo. Esa cualidad la comparte con los planteos de las teorías del crecimiento endógeno (Vázquez-Barquero, 2002b). La particularidad es que en ese proceso el territorio juega un papel central y no es un simple telón de fondo. La endogeneidad del desarrollo desde esta perspectiva, según Boisier (1993), se manifiesta en cuatro planos que se entrecruzan: político, económico, tecnológico y cultural. 
La endogeneidad en lo político se refiere a la capacidad del territorio para tomar decisiones relevantes en relación con el proceso de desarrollo. En lo económico, implica capacidad de apropiación y reinversión en el territorio de parte del excedente generado. En el plano tecnológico, se refiere a la capacidad interna de un territorio para generar sus propios impulsos de cambio. Por último, en el plano de la cultura, la endogeneidad es planteada como una suerte de matriz generadora de identidad socioterritorial que, junto a los otros planos, permite un espacio de interacción y sinergia entre una variedad de actores locales, públicos y privados, lo que favorece el cambio estructural y el desarrollo.

Por otra parte, el enfoque asumido en este artículo tiene también un fuerte énfasis en la innovación; en este sentido, tiene raíces en algunos planteamientos de Schumpeter (1934), quien sitúa a la innovación como motor del desarrollo el cual se asume como un antecedente muy temprano que reivindica el rol de los actores en el desarrollo, más allá de los agregados macroeconómicos (en ese caso un determinado tipo de actor, el entrepreneur schumpeteriano).

Sin embargo, la innovación se considera en este trabajo en un sentido amplio, no sólo referida a cambios radicales (que se asocia más al enfoque schumpeteriano) sino también a innovaciones incrementales que refieren adaptaciones y cambios en los productos, los insumos, la producción, la organización o la comercialización.

La diferencia con otros enfoques, desde la mirada territorial, radica en que la innovación resulta de la interacción entre actores e instituciones que están asociados a un espacio territorial concreto y, a su vez, condicionados por una trayectoria común dada por la historia, la geografía y las costumbres de sus habitantes.

$\mathrm{Al}$ respecto, los enfoques evolucionistas ${ }^{1}$ son una buena aproximación ya que plantean la idea de los sistemas nacionales de innovación en diálogo con sistemas regionales, donde la localización geográfica es muy importante y se relaciona con los componentes tácitos del conocimiento, el peso de la historia y la trayectoria en los procesos de desarrollo. De todas formas, una aproximación más definitiva a la mirada territorial surge del Groupe de Recherche Européen pour les Milieux Innovateurs (GREMI), que habla de entornos innovadores.

Según Aydalot (1986), el acceso al conocimiento, el papel del tejido productivo en su difusión, el impacto de la proximidad de un mercado, o la existencia de trabajadores calificados, son factores que explican la aparición de zonas geográficas con mayor o menor capacidad innovadora. Para Maillat (1995) es fundamental la capacidad de aprendizaje de

${ }^{1}$ A partir del trabajo de Nelson y Winter (1974), entre otros aportes. 
los actores locales, quienes deben dinamizar y transformar el entorno a través de sus decisiones de inversión y producción, y lograr un sistema productivo local competitivo.

\subsection{Aglomeraciones urbanas, periferia y desarrollo}

Hay varios autores que relacionan la configuración de las aglomeraciones urbanas y la distribución de la actividad económica en el espacio con el proceso de globalización o economía mundo dentro de la economía capitalista. Entre ellos, sin agotar la lista, Harvey (1990) plantea que uno de los ejes de la modernización capitalista es la aceleración del ritmo de los procesos económicos y sociales, lo que incrementa la velocidad de retorno del capital y supera las barreras espaciales (gracias a los avances tecnológicos, de la comunicación y la infraestructura de transporte), asimismo, conduce a la formación de un mercado mundial.

Sin embargo, esa misma superación de las barreras espaciales requiere de la necesaria formación de configuraciones socio espaciales fijas e inmóviles que se refieren a aglomeraciones y complejos industriales localizados, con sistemas de redes de transporte y comunicación a gran escala.

Castells (2000) plantea la globalización como la articulación en tiempo real de actividades sociales localizadas en espacios geográficos diferentes, con características sociales, culturales, físicas y funcionales bien definidas, donde el espacio de flujos es la nueva forma espacial característica de las prácticas sociales que dominan y conforman la sociedad red. Por su parte, Veltz (1999) plantea que se asiste a una reconfiguración como forma de superar la crisis del paradigma fordista a través de nuevas maneras de organización flexibles de las empresas a nivel global, lo que crea un mapa económico-geográfico mundial de redes intrincadas, y da lugar a lo que el autor ha llamado la economía del archipiélago.

El papel de los centros urbanos en la localización de la actividad productiva ha sido explicado por algunos autores a través de la relación de intercambio o trade off entre economías de escala y costos de transporte. Krugman $(1991,1995)$ explica, en su modelo centro-periferia, cómo las firmas se localizan en el territorio, y analiza la forma de maximizar la obtención de economías de escala con los menores costos de transporte por localizar la producción en un lugar y abastecer, desde allí, a los mercados de destino, ${ }^{2}$ los primeros representan una fuerza centrífuga y los segundos una fuerza centrípeta.

${ }^{2}$ Entre los modelos pioneros en la economía espacial están los trabajos de Von Thunen de 1826, y la Central Place Theory atribuida a Christaller (1933) y Losch (1944) (citados en Keilbach, 2000). 
Adicionalmente, las regiones que cuentan con importantes aglomeraciones urbanas cuentan también con economías pecuniarias ${ }^{3}$ asociadas al tamaño del mercado, lo que genera espacios propicios para atraer actividades económicas, trabajadores y consumidores. Si se considera, como lo hace Fujita (1992), que los consumidores presentan en su función de utilidad una preferencia por la variedad, ${ }^{4}$ entonces más consumidores se verán atraídos por las ciudades que presentan mayor variedad de bienes y servicios, lo que genera mayores economías pecuniarias y atrae a más empresas permitiendo una mayor variedad de bienes y reforzando el proceso.

A su vez, hay economías de urbanización que refieren aspectos más generales vinculados a las ventajas de un mejor y más barato acceso a infraestructuras de servicios (energía, agua, comunicaciones, aeropuertos y puertos), a empresas de servicios estratégicos y a un mercado de trabajo con mayor calificación (Keilbach, 2000; Conventz et al., 2014).

Recientemente, se han realizado trabajos que se centran en el estudio de las ciudades o regiones inteligentes o basadas en el conocimiento. Algunos ponen énfasis en las aglomeraciones de firmas altamente intensivas en conocimiento y las estrategias de desarrollo urbano adecuadas para promover tales emprendimientos (Hsieh, 2014), otros en la interrelación entre las infraestructuras y la conectividad de las ciudades, así como en la generación de esas economías intensivas en conocimiento (Conventz et al., 2014), y otros en la cultura local como factor estratégico de planificación urbana y regional (Fachinelli et al., 2014).

Por otra parte, este desarrollo de sectores altamente intensivos en conocimiento apoyados en importantes infraestructuras y existencia de capital humano altamente calificado persistentemente en el tiempo tiende a ser localizado y a reforzar a las aglomeraciones urbanas que le dan sustento (Vogiatzoglou-Tsekeris, 2013 y Jofre-Monseny et al., 2014). En cualquier caso, estos análisis se aplican a territorios centrales o con roles estratégicos en los sistemas urbanos y regionales nacionales e internacionales.

$\mathrm{Al}$ pasar de la teoría a la observación lo que sucede en los países de América Latina respecto a las diferencias de desarrollo económico relativo entre territorios, por ejemplo, aproximado por ingreso o producto interno bruto (РІв) per cápita, se puede decir que, en general, los territorios que muestran mejores posiciones son los que presentan concentraciones urbanas con roles centrales en los respectivos países.

En Brasil, ${ }^{5}$ por ejemplo, el estado de San Pablo tiene un PIB per cápita que es una vez y media el valor promedio del país (en términos de un

\footnotetext{
${ }^{3}$ Ventajas que son de tipo monetario y operan a través del mercado (precios).

${ }^{4}$ Las economías de diversidad fueron planteadas anteriormente por Jacobs en 1969.

${ }^{5}$ Datos del Instituto Brasilero de Geografía y Estadística (IBGE) para 2009, disponible en: http:// www.sidra.ibge.gov.br/bda/pesquisas/PIBMun/default.asp.
} 
índice con base 100 en la media para Brasil, el valor para San Pablo es 154, mientras que el estado de Ceará (en el nordeste) tiene un valor algo menor que la mitad del valor promedio nacional (45). A su vez, hay tres municipios de Ceará que tienen un PIв per cápita superior a la media para Brasil: Eusébio (155), Horizonte (116) y Maracanaú (104), todos territorios que conforman la región metropolitana de la ciudad de Fortaleza (la más grande de ese estado y la quinta de Brasil). Por otra parte, si se observa cuáles son los municipios de ese estado con menor PIB per cápita se puede apreciar que son los que se localizan en situación periférica respecto a la región metropolitana (Poranga, Martinópole y Catarina, con valores entre $15 \%$ y $17 \%$ de la media nacional).

En Colombia los departamentos que poseen metrópolis importantes o están situados próximos a éstas también tienen un mejor posicionamiento en el contexto nacional. En Ramírez et al. (2007) se elabora una clasificación de los departamentos según escalafones de competitividad; se evidencia una relación espacial con una marcada estructura de centroperiferia, donde los departamentos líderes (más competitivos) son aquellos que albergan a las ciudades más importantes de Colombia y sus zonas de influencia. De esta forma, en las cinco regiones en las que agrupan a los departamentos (Caribe, Nororiental, Noroccidental, Central y Suroccidental) las mejores posiciones corresponden a Atlántico, Santander, Antioquía, Bogotá y Valle, donde se ubican las grandes capitales del país (Barranquilla, Bucaramanga, Medellín, Bogotá y Cali).

También en Uruguay ocurren procesos similares. En RodríguezMiranda (2006) se muestra cómo las economías de aglomeración urbana han sido un factor relevante para explicar el desarrollo de la zona sur y litoral oeste, a la vez que contribuyen a explicar (por ausencia) las dificultades en el desarrollo de las regiones más aisladas y menos pobladas del norte del país.

\subsection{Innovación y organización de la producción en economías locales interiores}

Como señala la teoría del entorno innovador, es necesario que exista un entramado productivo particular para generar capacidad de innovación en el territorio, y para ello es fundamental que existan relaciones locales importantes. Desde esta perspectiva, para el surgimiento de un entorno innovador son necesarias ciertas condiciones favorables de recursos humanos, tradición y cultura productiva, actores locales capaces de concretar condiciones previas favorables o nuevas oportunidades que se presentan, capacidad de aprendizaje y difusión en el territorio, cooperación, concertación y negociación (Méndez, 2000). 
Sin embargo, en las economías locales interiores las trayectorias históricas en general están vinculadas a sectores productivos tradicionales de baja intensidad innovadora, poco demandantes de trabajo altamente calificado y de servicios de mediana y alta complejidad, en sociedades también tradicionales (de base agraria) y sin economías de aglomeración relevantes. Por lo tanto, no es raro que las articulaciones económicas locales también sean débiles. En este contexto será más probable observar desarrollos sectoriales y no procesos de desarrollo territorial.

Como ejemplo de las dificultades que pueden enfrentar los territorios que no tienen condiciones de partida favorables, Diez y Verna-Etcheber (2012) analizan la experiencia de conformación de un distrito metalmecánico (Dimsur) en el sudoeste de la Provincia de Buenos Aires (Argentina), en una región con una estructura productiva ligada a la actividad agropecuaria y al Puerto de Bahía Blanca, sin tradición industrial y periférica respecto de la ciudad de Buenos Aires y su cono urbano.

Encuentran que, a pesar de que la iniciativa surge con fuerte apoyo de la Universidad Tecnológica Nacional y de la política pública, se evidencian severas restricciones vinculadas a la falta de recursos y a la ausencia de un capital social consolidado. Incluso, cuando se generan iniciativas de redes entre empresas con impacto verificado en términos de innovación, los beneficios generados y las ventajas del ambiente de red pueden ser apropiados por pocas empresas y, por lo tanto, tener un menor impacto transformador de la economía local. Esto parece suceder, por ejemplo, en el Arranjo Produtivo Local (APL) de Confecciones en la mesoregión del Agreste Pernambucano en Brasil (Ferreira et al., 2012).

Dicho de otra forma, la organización productiva en las economías locales interiores no favorece frecuentemente el desarrollo territorial; esto tiene puntos de contacto con algunos análisis del desarrollo en términos de países y sistema económico mundial que refieren al cambio estructural, la diversificación productiva y los procesos de aprendizaje. En efecto, con cierto cuidado, se pueden recoger algunos de esos planteamientos para el caso del análisis territorial.

$\mathrm{Al}$ respecto de la innovación y la tecnología, es de interés mencionar los aportes de las teorías estructuralistas que destacan el papel de la estructura productiva en el desarrollo de largo plazo. ${ }^{6}$ En un análisis a nivel de países puede ser convincente decir que si un país no desarrolla sectores de tecnología media-alta verá aumentada la brecha de desarrollo con los países que ya han generado esa transformación en su estructura productiva. Si analizamos una región con cierto rezago relativo no es razonable que se le exija un cambio estructural como el que se le puede pedir a un

${ }^{6}$ Ver Cimoli (2005) y Porcile et al. (2006). 
país. De hecho los sectores de alta tecnología ( high tech) tendrán su oportunidad de desarrollo en las áreas metropolitanas y sus zonas de influencia, y no es razonable pretender que ello ocurra en regiones alejadas de las grandes economías de aglomeración.

Sin embargo, es importante reconocer que los sectores de corte más tradicional, que se caracterizan por tecnología baja (paradigmas maduros), muchas veces basados en recursos naturales y poco demandantes de recursos humanos de alta calificación, presentan dificultades a la hora de articular relaciones económicas locales relevantes y con potencial de desarrollo para el territorio. En este sentido, también habría que exigir a una economía local interior cierto impulso de cambio estructural, pero adecuado a sus posibilidades, para poder transitar hacia interrelaciones locales más fuertes y hacia una mayor capacidad de innovación.

Otros estudios plantean la diversidad como factor de desarrollo. Por ejemplo, Saviotti y Pika (2004) señalan que la diversidad de sectores juega un papel importante en la sostenibilidad del desarrollo a largo plazo. Sólo es posible el crecimiento a largo plazo si surgen nuevos sectores que desplazan a los preexistentes, generando nueva capacidad de creación de empleo junto con aumento de la productividad. Además, señalan que la tasa de creación de nuevos sectores y la productividad de la economía no son situaciones independientes sino que son procesos complementarios que se refuerzan. En el caso de una economía local interior también puede resultar importante que exista una diversidad sectorial incluso dentro de una especialización general. Es decir, que no dependa toda la economía local de un único sector o incluso de una única gran empresa.

Por otro lado, Hidalgo et al. (2007) introducen el concepto de espacio de producto, que se basa en la idea de que las nuevas producciones tienden a ser bienes próximos a los que ya se producen. Es decir, que las economías van avanzando en la producción de bienes según van adaptando sus capacidades, las que se relacionan con los bienes ya producidos.

A su vez, los bienes manufactureros y más intensivos en conocimiento presentan relaciones más densas entre sí, lo que permite dar saltos más accesibles de un bien menos sofisticado a otro de mayor complejidad. En cambio, los bienes basados en recursos naturales presentan espacios de producto menos densos y conectados, lo que implica saltos mayores para pasar a la producción de bienes más sofisticados. Al pensar en localidades y regiones interiores, la búsqueda de una diversificación de la actividad económica y el impulso a nuevas actividades que, aún relacionadas con las tradicionales, puedan tener algún grado de novedad para el territorio, pueden ser formas válidas para ir ampliando ese espacio de producto local.

A la luz del los párrafos anteriores parece una cuestión crítica para el análisis de las economías locales interiores comprender cómo funcionan 
sus principales sectores productivos, cómo se comportan respecto a la capacidad de innovación y al relacionamiento con la economía local, para poder apoyar transformaciones que puedan impulsar cambios hacia la conformación de un sistema productivo competitivo, capaz de generar desarrollo en el territorio.

Todo esto al tener en cuenta la especificidad de las economías locales interiores que resumimos en las siguientes características: i) economías que se sitúan en regiones que presentan una desventaja en el contexto nacional respecto a las economías de aglomeraciones urbanas; ii) economías cuyos desarrollos productivos más importantes y competitivos se relacionan con actividades de base primaria y tecnología baja, y que suelen concentrarse en pocos rubros; iii) en definitiva, economías con estructuras productivas poco diversificadas y con sectores poco intensivos en conocimiento y capital humano calificado.

\section{Desarrollo sectorial vs territorial: un modelo de análisis}

El objetivo del modelo es explicar cómo son las dinámicas económicas productivas localizadas en el territorio desde el punto de vista de la capacidad de innovación y las interrelaciones económicas locales, de forma tal que se pueda caracterizar a las economías interiores de acuerdo a si se corresponden con procesos sectoriales innovadores o no innovadores y en qué medida los mismos implican (o no) interrelaciones económicas con el resto de la economía local.

Se propone un modelo sencillo y que pueda ser aplicado en contextos de falta de datos estadísticos oficiales con la desagregación territorial necesaria y actualizada. Por otra parte, se trata de un enfoque que busca realizar un diagnóstico oportuno (en plazos) para que pueda guiar la intervención en pos del desarrollo local, es decir, orientado a la acción. Adicionalmente, la información también debe ser relativamente sencilla de obtener en diversas situaciones permitiendo la comparación de diferentes economias interiores.

La información se obtiene de i) información estadística oficial básica referida a empleo por sectores de actividad, apoyando ese análisis en la revisión de documentación existente (estudios territoriales o información estadística existente); y ii) la realización de entrevistas propias a informantes calificados y actores económicos locales.

Un paso previo consiste en diferenciar entre los sectores económicos que tienen alguna capacidad de transformación productiva y aquellos que pueden ser clasificados como seguidores, en tanto que se puede decir que responden a lo que sucede con el promedio de la economía local (no constituyen fuente de cambios en la dinámica económica local). De esta 
forma, el análisis se enfocará en los sectores con capacidad de transformación productiva. Un ejemplo de sector seguidor es la administración pública o el sector de servicio doméstico, que no generan por sí mismos procesos de transformación productiva en la economía local, sino que responden a demandas o necesidades de otros procesos que ocurren en ella. A su vez, la enseñanza y la salud, en general, serán sectores seguidores ya que acompañan las necesidades básicas de la población local en cada uno de esos ámbitos.

En general, las industrias (en su mayoría agroindustrias), las actividades productivas en el medio agropecuario y los servicios productivos logísticos y técnicos asociados a estos rubros son sectores con potencial transformador de la economía local. Por supuesto que las actividades intensivas en tecnología y conocimiento son también típicamente de potencial transformador, pero es menos probable que se encuentren en este tipo de economía local. También es relevante considerar las actividades de servicios relacionadas con el comercio, el esparcimiento y el turismo; de hecho, en muchas de estas economías estos sectores pueden tener potencial para la generación de empleo y el desarrollo de actividades competitivas.

\subsection{Las dimensiones de análisis e indicadores}

Se analizan dos dimensiones claves que son la innovación y las interrelaciones económicas locales. Como ya se señaló antes, el concepto de innovación utilizado se asocia a las adaptaciones y mejoras incrementales antes que radicales. Por otra parte, en este tipo de economía no tiene demasiado sentido plantear un análisis de la capacidad de innovación que tome como aspecto central la discriminación, por ejemplo, entre sectores industriales de alta tecnología, tecnología media, tecnología baja y sectores basados en recursos naturales. ${ }^{7}$ En primer lugar, en estas economías los sectores de servicios pueden ser tan o más importantes que los sectores industriales. Pero lo más importante es que a escala local no se puede reproducir un análisis que puede ser adecuado en la escala nacional. Las economías locales interiores, pequeñas y alejadas de las economías de aglomeraciones urbanas, seguramente no serán el escenario donde un país pueda generar el salto cualitativo hacia la alta tecnología. ${ }^{8}$

Sin embargo, las economías locales interiores pueden aspirar a tener trayectorias que impliquen mejoras importantes en el contenido tecno-

\footnotetext{
${ }^{7}$ Por ejemplo, las clasificaciones que se realizan en los estudios que comparan países, como en Hatzichronoglu (1997) o en Lall (2000).

${ }^{8} \mathrm{Al}$ respecto, un estudio prospectivo para Uruguay al 2030 (opp, 2009) que plantea diversos escenarios de desarrollo sectorial para el país, muestra que siempre los desarrollos de sectores como el software y la farmacéutica veterinaria (que ya tienen un desarrollo interesante), o la biotecnología y la nanotecnología (que aún son incipientes) se concentran en la capital del país y su área metropolitana.
} 
lógico y la intensidad en conocimiento en sus productos y servicios. Incluso sobre la base de los sectores intensivos en recursos naturales se puede avanzar en cadenas de valor, por ejemplo, pasar de producir troncos a producir tableros y de producir tableros a producir partes de muebles.

Se puede agregar conocimiento mediante servicios a la producción primaria, mejora genética, adaptaciones a la realidad local de maquinarias o aplicaciones de software. Es posible también comenzar a sustituir insumos que se importan y para los que no se necesitan grandes economías de escala. Se puede avanzar en mejoras en logística y transporte, inteligencia competitiva para la exportación, montaje y mantenimiento industrial, entre otros. Se pueden desarrollar servicios turísticos que puedan competir con otras ofertas a nivel nacional.

Respecto a la dimensión de las interrelaciones locales, tampoco es de esperar que estas economías locales desarrollen como regla fuertes relaciones económicas entre sus empresas y actores económicos, esto se debe a la propia naturaleza de los sectores productivos que están presentes, como ya se ha señalado. Por lo tanto, el análisis pertinente refiere a la identificación de los sectores que desarrollan en alguna forma vínculos con otras empresas (proveedores, servicios, acuerdos de cooperación) y que participan en forma activa (o incluso liderando) en algún ámbito de asociación entre actores locales.

Para hacer operativas las dos dimensiones claves del análisis se construyen indicadores que pueden ser elaborados de forma relativamente sencilla para cada uno de los sectores con potencial transformador. El indicador de innovación es un promedio simple de tres subindicadores: i) competitividad en los mercados; ii) tecnología; iii) calificación de los recursos humanos. El indicador de interrelaciones económicas locales es un promedio simple de tres subindicadores: i) relación con proveedores y servicios locales; ii) participación de las empresas en instituciones y asociaciones locales (de investigación, productivas o gremiales); iii) cooperación y acuerdos en el sector (en sentido amplio, para producción, comercialización, inversión, capacitación e investigación). Cada subindicador se construye en forma cualitativa utilizando una escala discreta de 0 a 3, donde 3 es el mejor valor que se puede obtener. Los criterios para la calificación se muestran en los cuadros 1 y 2 . Se trata de criterios que recogen situaciones bastante diferenciadas, que pueden determinarse con aceptable nivel de precisión a partir del trabajo de campo (entrevistas).

El cuadro 1 muestra los tres subindicadores que se utilizan para aproximar la dimensión de innovación. Uno de ellos refiere a la competitividad en los mercados. Se entiende que pasar la prueba del mercado y penetrar mercados más exigentes que el local (el nacional y la exportación) es una buena aproximación a capacidades innovadoras. Por otra parte, el subin- 


\section{Cuadro 1 \\ Indicador de innovación (promedio simple)}

\begin{tabular}{|c|c|c|}
\hline $\begin{array}{c}\text { Competitividad en } \\
\text { mercados } \\
\text { (pondera: } 1 / 3 \text { ) }\end{array}$ & $\begin{array}{c}\text { Tecnología } \\
\text { (pondera: 1/3) }\end{array}$ & $\begin{array}{l}\text { Calificación de los } R R H H \\
\text { (pondera: 1/3) }\end{array}$ \\
\hline $\begin{array}{l}0 \text { - No es económicamente } \\
\text { viable o depende crítica- } \\
\text { mente de política pública } \\
\text { (subsidio) }\end{array}$ & $\begin{array}{l}0 \text { - Debajo del estándar } \\
\text { promedio nacional para la } \\
\text { actividad }\end{array}$ & $\begin{array}{l}0 \text { - No demanda RRHH cali- } \\
\text { ficados ni especializados }\end{array}$ \\
\hline $\begin{array}{l}1 \text { - Compite en el mercado } \\
\text { local (es el mercado relevan- } \\
\text { te para el sector) }\end{array}$ & $\begin{array}{l}1 \text { - Mayor o igual que el } \\
\text { estándar promedio nacional } \\
\text { para la actividad (si es la } \\
\text { mejor disponible a nivel } \\
\text { nacional es 2) }\end{array}$ & $\begin{array}{l}1 \text { - Requerimientos bajos de } \\
\text { calificación o especializa- } \\
\text { ción** }\end{array}$ \\
\hline $\begin{array}{l}2 \text { - Compite en mercados } \\
\text { regionales y nacionales (es } \\
\text { el mercado relevante para el } \\
\text { sector) }\end{array}$ & $\begin{array}{l}2 \text { - Mejor tecnología dispo- } \\
\text { nible para la actividad a } \\
\text { nivel nacional (si también } \\
\text { es la mejor disponible a } \\
\text { nivel internacional es 3) }\end{array}$ & $\begin{array}{l}2 \text { - Requerimientos medios- } \\
\text { altos de calificación y espe- } \\
\text { cialización*** de RRHH con } \\
\text { problemas en la oferta local }\end{array}$ \\
\hline $\begin{array}{l}3 \text { - Compite en mercados } \\
\text { internacionales (es el merca- } \\
\text { do relevante para el sector) }\end{array}$ & $\begin{array}{l}3 \text { - Mejor tecnología dispo- } \\
\text { nible para la actividad a } \\
\text { nivel internacional }\end{array}$ & $\begin{array}{l}3 \text { - Requerimientos medios- } \\
\text { altos de calificación y espe- } \\
\text { cialización*** de RRHH con } \\
\text { adecuada oferta local }\end{array}$ \\
\hline
\end{tabular}

** Un criterio que puede ayudar es considerar si la remuneración promedio en el sector es igual o inferior al promedio del mercado local.

*** Como criterio se puede considerar si la remuneración promedio del sector es superior al promedio del mercado local o si exige una cultura productiva/comercial específica. Que existan problemas en la oferta local de ese tipo de RRHH requerido limita el potencial innovador del sector, una oferta local adecuada, por el contrario, lo potencia.

Fuente: elaboración propia.

dicador de tecnología refiere la comparación que utiliza el sector en función de la mejor disponible para dicha actividad a nivel nacional e internacional (indicador de brecha tecnológica). En el caso de los servicios la tecnología puede referir aspectos técnicos, por ejemplo, software y equipamiento que se utiliza, pero también aspectos organizacionales. Por último, la calificación de los recursos humanos que requiere un sector es también una forma de aproximar la complejidad de los procesos y productos que en el mismo se producen.

El cuadro 2 presenta los tres subindicadores para aproximar las interrelaciones locales. Uno refiere la medida en que los sectores desarrollan vínculos con proveedores y servicios locales en aspectos relevantes para el negocio. No se consideran como servicios limpieza, jardinería, alimentación de personal, seguridad o similares. A su vez, se diferencia entre las situaciones en las que se recurre a proveedores locales en forma puntual 


\section{Cuadro 2 \\ Indicador de interrelaciones económicas locales (promedio simple)}

\begin{tabular}{|c|c|c|}
\hline $\begin{array}{c}\text { Proveedores y servicios } \\
\text { locales* } \\
\text { (pondera: } 1 / 3 \text { ) }\end{array}$ & $\begin{array}{c}\text { Participación de los actores } \\
\text { de la actividad en } \\
\text { instituciones y asociaciones } \\
\text { locales } \\
\text { (pondera: } 1 / 3 \text { ) }\end{array}$ & $\begin{array}{c}\text { Cooperación y acuerdos entre } \\
\text { empresas/instituciones } \\
\text { locales }{ }^{* * *} \\
\text { (pondera: } 1 / 3)\end{array}$ \\
\hline $\begin{array}{l}0 \text { - No tiene relación o no } \\
\text { existen }\end{array}$ & $\begin{array}{l}0 \text { - No hay participación y } \\
\text { no hay ámbitos locales para } \\
\text { ello }\end{array}$ & 0 - No hay \\
\hline $\begin{array}{l}1 \text { - Adquiere en forma pun- } \\
\text { tual o coyuntural }\end{array}$ & $\begin{array}{l}1 \text { - Participación puntual o } \\
\text { no representativa de la acti- } \\
\text { vidad }\end{array}$ & $\begin{array}{l}1 \text { - Se realizan en forma } \\
\text { puntual o coyuntural }\end{array}$ \\
\hline $\begin{array}{l}2 \text { - Al menos en algún } \\
\text { aspecto de la actividad se } \\
\text { adquiere en forma regular }\end{array}$ & $\begin{array}{l}2 \text { - Participación regular y } \\
\text { representativa de la activi- } \\
\text { dad }\end{array}$ & $\begin{array}{l}2 \text { - Se realizan en forma más } \\
\text { o menos regular (formales o } \\
\text { informales) }\end{array}$ \\
\hline $\begin{array}{l}3 \text { - Contratos o acuerdos } \\
\text { con horizontes de largo } \\
\text { plazo }\end{array}$ & $\begin{array}{l}3 \text { - Participación regular y } \\
\text { representativa de la activi- } \\
\text { dad, con rasgos de liderazgo } \\
\text { sobre la economía y socie- } \\
\text { dad local }\end{array}$ & $\begin{array}{l}3 \text { - Contratos o acuerdos con } \\
\text { horizontes de largo plazo }\end{array}$ \\
\hline
\end{tabular}

\footnotetext{
* Aspectos que influyen en la ecuación de competitividad de la empresa (por ejemplo, insumos productivos, servicios que afectan los costos de producción, servicios de logística). No corresponden, por ejemplo, servicios de jardinería, limpieza, seguridad, y otros que no se relacionan con el proceso productivo o la actividad del negocio.

** Instituciones u organizaciones de investigación, productivas o gremiales.

*** Cooperación o acuerdos en producción, inversión, comercialización, capacitación, investigación. Fuente: elaboración propia.
}

o esporádica, cuando se establecen relaciones estables (se recurre regularmente a ese proveedor), y cuando existen relaciones de largo plazo con acuerdos entre las partes.

Otro subindicador refiere la participación de las empresas del sector en organizaciones y asociaciones locales, relacionadas, por ejemplo, con asuntos gremiales, investigación o para promover el sector, o incluso preocupadas por el desarrollo del territorio. Cuando hay participación se diferencia entre participación puntual o escasamente representativa del sector; cuando ésta es regular y representativa del sector; y cuando las empresas, a través de esa participación, adquieren rasgos de liderazgo en la economía y sociedad local; por último, se considera un tercer subindicador de cooperación y acuerdos en el sector. En este caso se analiza si las empresas en el sector realizan acuerdos o cooperan, diferenciando si son hechos puntuales, prácticas regulares (formales o no) y si hay contratos o acuerdos a largo plazo. 
Figura I

Modelo S-T

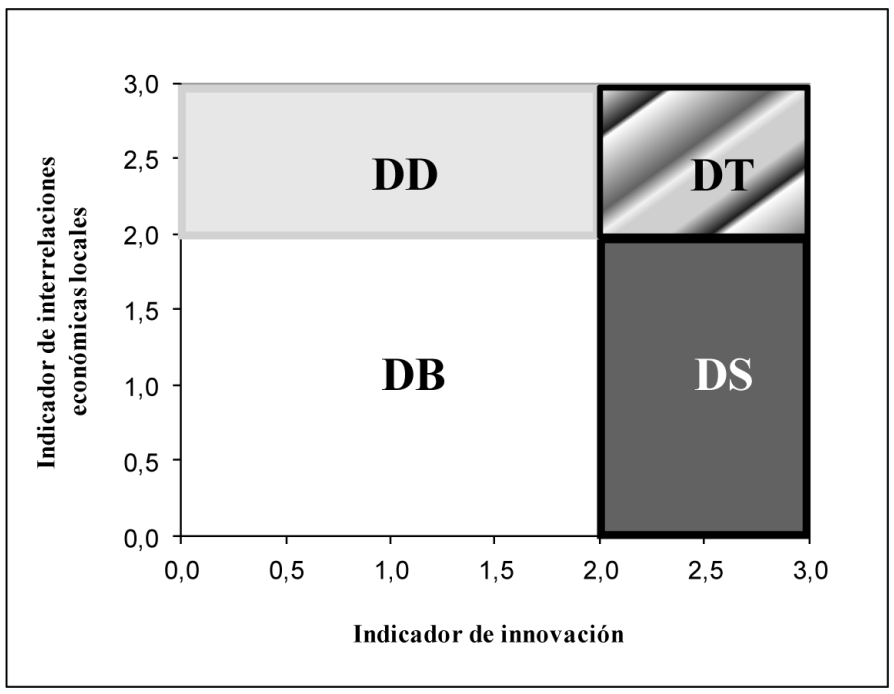

Fuente: elaboración propia.

\subsection{El modelo $S$ - $T$}

La sigla S-T refiere a la disyuntiva entre desarrollo sectorial (DS) y desarrollo territorial ( $\mathrm{DT})$. Por lo tanto, el modelo S-T caracteriza las trayectorias de desarrollo de un territorio a partir de las dimensiones de innovación y de interrelaciones económicas locales, lo que permite un análisis en el plano que determina cuatro cuadrantes, como se muestra en la figura I.

El cuadrante que sitúa a ambos indicadores en valores entre 0 y 2 refiere a una situación de desarrollo bajo (DB) en el territorio, es decir, los sectores con potencial de transformación que se ubiquen en este cuadrante realizan un aporte bajo en términos de desarrollo territorial, tanto desde el punto de vista de la innovación como desde la articulación con la economía local.

El cuadrante que resulta de valores entre 2 y 3 del indicador de interrelaciones económicas locales y entre 0 y 2 del indicador de innovación refiere a una situación de desarrollo defensivo (DD). En este caso, los sectores desarrollan vínculos con la economía local pero no logran hacerlo en clave competitiva e innovadora. Por lo tanto, el tejido productivo local que se configura tendrá rasgos defensivos o de supervivencia, en vez de potenciar una inserción competitiva del territorio. El cuadrante que resulta de valores entre 2 y 3 del indicador de innovación y entre 0 y 2 
del indicador de interrelaciones locales refleja una situación de desarrollo sectorial (Ds).

Es decir, que los sectores que se ubican en este cuadrante muestran desarrollos competitivos sectoriales con desconexión del resto de la economía local. Finalmente, el cuadrante que supone valores entre 2 y 3 para ambos indicadores refleja una situación favorable al desarrollo territorial (DT). Los sectores que se ubican en este cuadrante no solo muestran mejores condiciones de innovación y, por lo tanto, de competitividad, sino que son los que desarrollan vínculos más fuertes con la economía local.

En general, las economías locales interiores tenderán a presentar situaciones del tipo DB con actividades con baja capacidad de innovación y baja interrelación local. Sin embargo, puede haber territorios poco innovadores pero que cuenten con cierto acervo de capital social (por ejemplo, fruto de una determinada trayectoria histórica pasada o por la existencia de una fuerte identidad socio-territorial). En este caso es probable que el diagnóstico muestre un territorio en situación del tipo DD. Por otro lado, cuando existen en el territorio actividades con capacidad de innovación y competitivas a nivel nacional, o incluso internacional, en este tipo de economías interiores, lo más probable es que esto se refleje en un desarrollo del tipo DS.

Finalmente, hay que decir que la metodología es sensible a la capacidad técnica para la aplicación del trabajo de campo, es una limitación a tener en cuenta a la hora de su instrumentación. A su vez, si luego de un período prolongado de desarrollo territorial la economía local empieza a transitar hacia un cambio estructural más complejo, el modelo seguramente comenzará a perder poder explicativo y se deberá recurrir a otras herramientas que permitan analizar mejor la situación de sistemas productivos altamente desarrollados y con capacidades endógenas consolidadas. No sería útil este modelo para explicar, por ejemplo, cómo ha reaccionado la región italiana de Emilia-Romagna frente a la crisis europea, lo que implica entender cómo un espacio económico y social de desarrollo endógeno consolidado logra reinventarse y adaptarse a nuevos desafíos (Bianchi y Labory, 2011).

\section{El caso de Rivera (Uruguay) ¿¿desarrollo sectorial o territorial?}

\subsection{El caso de Rivera}

El departamento de Rivera está situado en el norte del Uruguay, limita al sur y suroeste con Tacuarembó, al este con Cerro Largo y al oeste con Artigas y Salto. Al norte y noreste limita con Brasil. Su principal ciudad 
es la capital Rivera (homónima) que se sitúa en la frontera con Brasil. El cuadro 3 muestra los principales datos demográficos de Rivera.

\section{Cuadro 3}

\section{Datos básicos de Rivera}

\begin{tabular}{lrrrrr}
\hline Territorio & Población & $\begin{array}{c}\text { \% Población } \\
\text { Rural }\end{array}$ & $\begin{array}{c}\text { \% Población } \\
\text { mujeres }\end{array}$ & $\begin{array}{c}\text { Superficie } \\
\mathrm{km}^{2}\end{array}$ & $\begin{array}{c}\text { Densidad de } \\
\text { población }\end{array}$ \\
\hline Rivera & 104,921 & $10.9 \%$ & $50.9 \%$ & 9,370 & 11.2 \\
Interior & $1,915,035$ & $11.2 \%$ & $50.5 \%$ & 174,486 & 11.0 \\
Montevideo & $1,325,968$ & $3.9 \%$ & $53.4 \%$ & 530 & $2,501.8$ \\
Total país & $3,241,003$ & $8.2 \%$ & $51.7 \%$ & 175,016 & 18.5 \\
\hline
\end{tabular}

Fuente: censo 2004 (INE, 2004).

El último dato disponible (2006) mostraba que Rivera representaba $1.8 \%$ del pIB total nacional. Los indicadores seleccionados en el cuadro 4 muestran desempeños económicos y sociales por debajo del promedio del país, propios de un territorio interior y periférico.

\section{Cuadro 4}

\section{Indicadores socioeconómicos seleccionados para Rivera}

\begin{tabular}{|c|c|c|c|c|c|}
\hline $\begin{array}{c}\text { Área } \\
\text { geográfica }\end{array}$ & $\begin{array}{c}\text { Participación } \\
\text { (\%) en el PIB } \\
\text { total del país, } \\
2006\end{array}$ & $\begin{array}{l}\text { Ingreso de los } \\
\text { hogares per } \\
\text { cápita } \\
\text { promedio, } \\
\text { 2010. Indice: } \\
\text { pais = } 100\end{array}$ & $\begin{array}{c}\text { Porcentaje } \\
\text { de personas } \\
\text { pobres, } \\
2010\end{array}$ & $\begin{array}{l}\text { Población } \\
\text { mayor de } 24 \\
\text { años que } \\
\text { aprobó } \\
\text { educación } \\
\text { primaria (6 } \\
\text { años), } 2010\end{array}$ & $\begin{array}{c}\text { Profesionales } \\
\text { y técnicos } \\
\text { universi- } \\
\text { tarios cada } \\
1000 \\
\text { habitantes, } \\
2010\end{array}$ \\
\hline Rivera & $1.8 \%$ & 74.6 & $21.3 \%$ & $45.7 \%$ & 7.8 \\
\hline Total país & $100.0 \%$ & 100.0 & $18.6 \%$ & $67.5 \%$ & 26.1 \\
\hline
\end{tabular}

Fuentes: datos de PIB de opp (Presidencia); datos de ingreso y pobreza a partir de procesamiento propio de la Encuesta Continua de Hogares del INE; datos de profesionales y técnicos con fuente en el registro de la Caja de Profesionales Universitarios de Uruguay.

A su vez, si se aproxima la distribución sectorial de la economía por el empleo con datos de la Encuesta Continua de Hogares (ECH) del Instituto Nacional de Estadística (INE), podemos decir que aproximadamente $19 \%$ del empleo está en el sector primario, y otro $19 \%$ en el sector secundario, $62 \%$ en el terciario. Si se considera que el sector secundario está representado básicamente por agroindustrias, energía y construcción, además de que la mayor parte de los servicios y el propio comercio se 
relacionan con las actividades del agro y la agroindustria, se puede ver que es una economía con fuerte base en recursos naturales.

\subsection{Identificación de sectores para el análisis y fuentes de información}

A partir de la revisión de antecedentes (cuadro 1A del anexo) y del procesamiento propio de datos de empleo de la ECH del INE se identifican los principales sectores de actividad (cuadro 5). Los sectores identificados con potencial transformador representan aproximadamente $51.2 \%$ del empleo total departamental. El restante $48.8 \%$ se explica por sectores que son seguidores. Se trata de la administración pública, la salud y la enseñanza (en conjunto 15.5\%); el servicio doméstico y otros servicios comunales, sociales y personales (14.3\%); la construcción (8.1\%); el correo, telecomunicaciones y energía (servicios de empresas públicas, en conjunto $3.3 \%$ ), y $7.6 \%$ que responde a una categoría residual.

\subsection{Análisis $S$-T para el caso de Rivera}

Se realizaron 23 entrevistas (sector empresarial, organizaciones locales, expertos y funcionarios del gobierno local) que se detallan en el cuadro $3 \mathrm{~A}$ del anexo. La figura II muestra los valores para los indicadores de innovación y de interrelaciones locales para cada sector analizado. En el cuadro $2 \mathrm{~A}$ del anexo se muestran los valores de cada indicador y sus componentes, por sector.

Se trata de una economía local que muestra a la mitad de sus sectores con potencial de transformación productiva y con indicadores de medios a altos de innovación (valores entre 2 y 3); así como otra mitad con indicadores bajos (menores a 2, e incluso entre 0 y 1 ). A su vez, casi todos los sectores con potencial transformador muestran bajos indicadores de interrelaciones locales. Por lo tanto, se trata de una economía local con alto grado de desarticulación interna, contexto en el que conviven sectores de alto dinamismo y competitividad con sectores de baja competitividad.

La figura III resume la información del modelo S-T con un análisis gráfico de las dos dimensiones de innovación y articulación local, considera, además, el peso de cada sector en el empleo de la economía local; dicho peso también se considera en el empleo y se observa que Rivera es una economía interior caracterizada por actividades de desarrollo bajo. Es decir, que presenta un bajo dinamismo competitivo e innovador, a la vez que no se articula en clave del sistema productivo local, además denota relaciones económicas locales débiles. Lo anterior contrasta con algunos desarrollos sectoriales importantes con actividades competitivas, tal como 


\section{Cuadro 5}

\section{Actividades con potencial transformador en Rivera}

\begin{tabular}{|c|c|c|}
\hline Actividad & Descripción & $\begin{array}{l}\text { \% en } \\
\text { empleo }\end{array}$ \\
\hline $\begin{array}{l}\text { Comercio, } \\
\text { restaurantes } \\
\text { y hoteles }\end{array}$ & $\begin{array}{l}\text { Actividades vinculadas al público consumidor final del } \\
\text { mercado local, en gran parte características de autoem- } \\
\text { pleo. El turismo que se recibe es de compras desde } \\
\text { Brasil (frontera), de muy baja permanencia (sólo horas), } \\
\text { que se dirige a los free shops. Este flujo es aprovechado } \\
\text { por algunas tiendas grandes (sucursales de firmas na- } \\
\text { cionales), además del consumo en restaurantes locales. }\end{array}$ & $17.2 \%$ \\
\hline $\begin{array}{l}\text { Cadena forestal } \\
\text { maderera }\end{array}$ & $\begin{array}{l}\text { Alta productividad de los suelos para la silvicultura e } \\
\text { incentivo de la ley nacional forestal de los noventa } \\
\text { (subsidio). Empresas nacionales y extranjeras, activida- } \\
\text { des que integran verticalmente fases primarias y secun- } \\
\text { darias. Los productos son madera aserrada y fundamen- } \\
\text { talmente tableros para la exportación. }\end{array}$ & $8.2 \%$ \\
\hline $\begin{array}{l}\text { Ganadería } \\
\text { mediana y grande }\end{array}$ & $\begin{array}{l}\text { Actividad tradicional en la región asociada al recurso } \\
\text { suelo, producción extensiva (predios mayores a 1,000 } \\
\text { hectáreas). }\end{array}$ & $7.9 \%$ \\
\hline $\begin{array}{l}\text { Pequeños } \\
\text { ganaderos }\end{array}$ & $\begin{array}{l}\text { Actividad tradicional en la región asociada al recurso } \\
\text { suelo, producción extensiva en predios pequeños (has- } \\
\text { ta } 1,000 \text { hectáreas). }\end{array}$ & $4.1 \%$ \\
\hline $\begin{array}{l}\text { Otros servicios } \\
\text { al agro y } \\
\text { agroindustria }\end{array}$ & $\begin{array}{l}\text { Agrupa un conjunto de actividades que se desarrollaron } \\
\text { en torno a la actividad del agro: servicios productivos } \\
\text { a los cultivos, elaboración de raciones, servicios veteri- } \\
\text { narios, reparación de maquinaria agrícola y agroindus- } \\
\text { trial (talleres de mecánica, electromecánica y tornerías). }\end{array}$ & $3.4 \%$ \\
\hline Free shops & $\begin{array}{l}\text { Surgen por ley en los ańos noventa (se instalaron más } \\
\text { de } 50 \text { en Rivera). Es un régimen de tiendas de frontera } \\
\text { que contempla comercios que sólo pueden vender a } \\
\text { extranjeros gozando de exoneración impositiva, por lo } \\
\text { que se especializan en ofrecer artículos importados de } \\
\text { alta calidad a un público brasileño de poder adquisiti- } \\
\text { vo alto (de ciudades del sur de Brasil). }\end{array}$ & $2.3 \%$ \\
\hline $\begin{array}{l}\text { Transporte de } \\
\text { carga y logística }\end{array}$ & $\begin{array}{l}\text { Dos empresas de capitales locales de más de } 30 \text { años } \\
\text { que trabajan a nivel nacional e internacional, a las que } \\
\text { se le suman otras empresas locales menores. }\end{array}$ & $2.0 \%$ \\
\hline Minería de oro & $\begin{array}{l}\text { La actividad surge a partir del recurso minero (yaci- } \\
\text { miento de oro) como emprendimiento extractivo ex- } \\
\text { plotado por capital extranjero }\end{array}$ & $2.0 \%$ \\
\hline Ladrillos & $\begin{array}{l}\text { Esta actividad surge hace pocos años con el apoyo del } \\
\text { gobierno local en articulación con políticas nacionales } \\
\text { como solución de empleo e ingresos para una población } \\
\text { en situación crítica. }\end{array}$ & $1.0 \%$ \\
\hline
\end{tabular}


Continúa...

\begin{tabular}{|c|c|c|}
\hline Actividad & Descripción & $\begin{array}{l}\% \text { en } \\
\text { empleo }\end{array}$ \\
\hline $\begin{array}{l}\text { Agroindustria } \\
\text { tabacalera }\end{array}$ & $\begin{array}{l}\text { La actividad surge como emprendimiento empresarial } \\
\text { hace más de } 100 \text { ańos, a partir de las condiciones cli- } \\
\text { máticas que permiten el cultivo del tabaco. Integra en } \\
\text { la misma firma las fases primaria y secundaria. }\end{array}$ & $0.9 \%$ \\
\hline $\begin{array}{l}\text { Horticultura } \\
\text { y granja }\end{array}$ & $\begin{array}{l}\text { En Tranqueras hay una tradición que viene de los años } \\
\text { cincuenta de producciones familiares de agricultura } \\
\text { intensiva para complementar ingresos ganaderos, pero } \\
\text { actualmente están en declive. La producción de cerdos } \\
\text { y aves ocurre en las cercanías de la ciudad de Rivera. }\end{array}$ & $0.4 \%$ \\
\hline $\begin{array}{l}\text { Agroindustria } \\
\text { láctea }\end{array}$ & $\begin{array}{l}\text { En los ochenta se organizó a los productores en una } \\
\text { cuenca regional ( } 120 \text { productores de los que hoy que- } \\
\text { dan } 37 \text { ) en torno a una planta de la firma nacional } \\
\text { Cooperativa Nacional de Productores de Leche } \\
\text { (Conaprole). Hoy funciona como centro de remisión } \\
\text { y de distribución para la región norte del país. }\end{array}$ & $0.4 \%$ \\
\hline $\begin{array}{l}\text { Venta materias } \\
\text { primas y maqui- } \\
\text { naria agrícola }\end{array}$ & $\begin{array}{l}\text { Esta categoría agrupa actividades comerciales que se } \\
\text { desarrollaron en torno a la actividad del agro: venta } \\
\text { de materias primas agropecuarias, barracas y comercio de } \\
\text { maquinaria agrícola. }\end{array}$ & $0.4 \%$ \\
\hline $\begin{array}{l}\text { Viñedos } \\
\text { y bodegas }\end{array}$ & $\begin{array}{l}\text { Presencia de una bodega importante (firma nacional) } \\
\text { con tradición centenaria y otros pocos pequeńos viñe- } \\
\text { dos de proyección local y regional. }\end{array}$ & $0.4 \%$ \\
\hline Apicultura & $\begin{array}{l}\text { Tiene algún desarrollo en forma reciente ligado al } \\
\text { crecimiento de la forestación. }\end{array}$ & $0.3 \%$ \\
\hline Arroz & $\begin{array}{l}\text { En el país, el cultivo data de 1930, adquiere impulso } \\
\text { con la creación por el gobierno de la Comisión Sectorial } \\
\text { del Arroz (1973). En Rivera se cultiva en la zona de } \\
\text { Vichadero por la influencia de productores brasileros. }\end{array}$ & $0.3 \%$ \\
\hline & Total en el empleo departamental & $51.2 \%$ \\
\hline
\end{tabular}

Fuentes: procesamiento propio de microdatos de ECH del INE (2004), datos del Ministerio de Ganadería Agricultura y Pesca y de Rodríguez-Miranda (2010a). 


\section{Figura II}

\section{Indicadores S-T para Rivera}

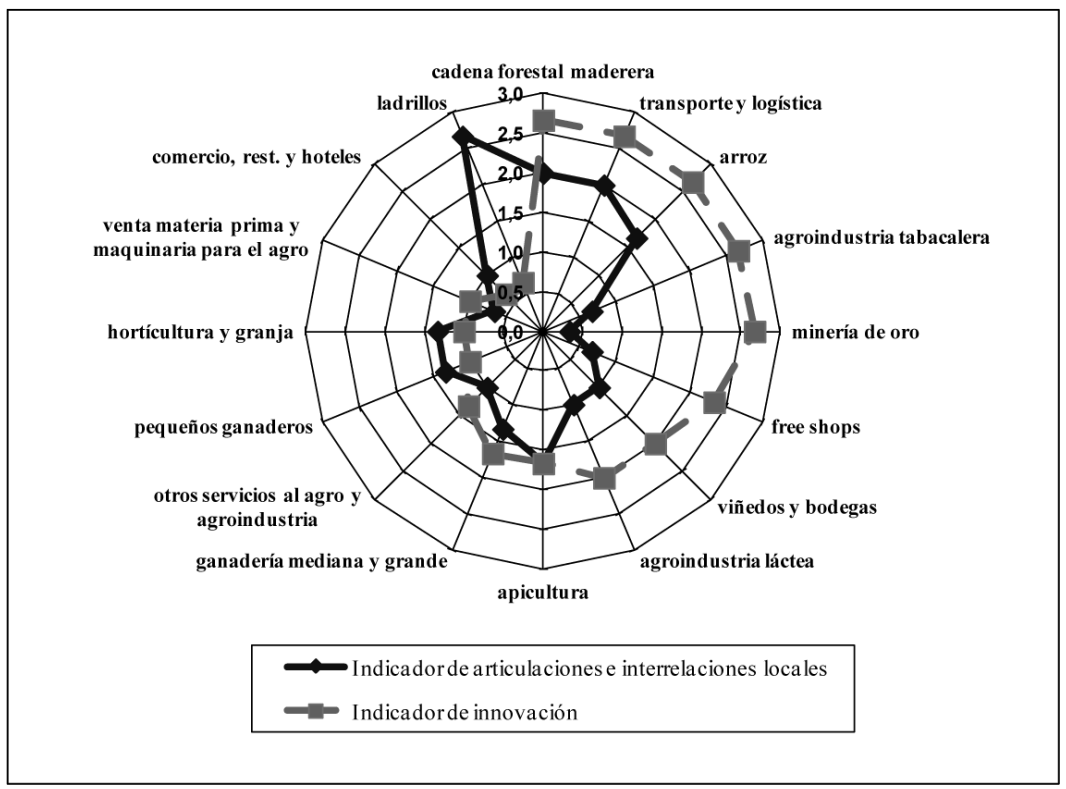

Fuente: elaboración propia.

la industria tabacalera, la minería y los free shops, los cuales no tienen una contribución importante para generar interrelaciones económicas locales. El arroz sigue este comportamiento aunque muestra un mayor grado de articulaciones locales; con la característica de bajo dinamismo pero con cierta capacidad de articulación se encuentra el sector de ladrilleros clasificado en la tipología de desarrollo defensivo.

Dentro del contexto general descrito es interesante identificar que la cadena forestal maderera y el transporte y logística son excepciones que presentan cierta capacidad para promover procesos de desarrollo territorial. Es decir, que presentan capacidad de innovación al mismo tiempo que establecen vínculos con el resto de la economía local. Sin embargo, los indicadores de interrelaciones locales no son altos, sino moderados (no mayores a dos), por lo que se podría decir que son sectores de comportamiento limítrofe entre los cuadrantes DS y DT.

El cuadro 6 muestra los valores promedio para los indicadores de interrelaciones locales y de innovación calculados para los grupos de sectores que se clasifican en las tipologías DB, DD, DS, y DT-DS. Estos mismos resultados se muestran en forma gráfica en la figura IV. 
Figura III

\section{Representación gráfica del análisis S-T para Rivera}

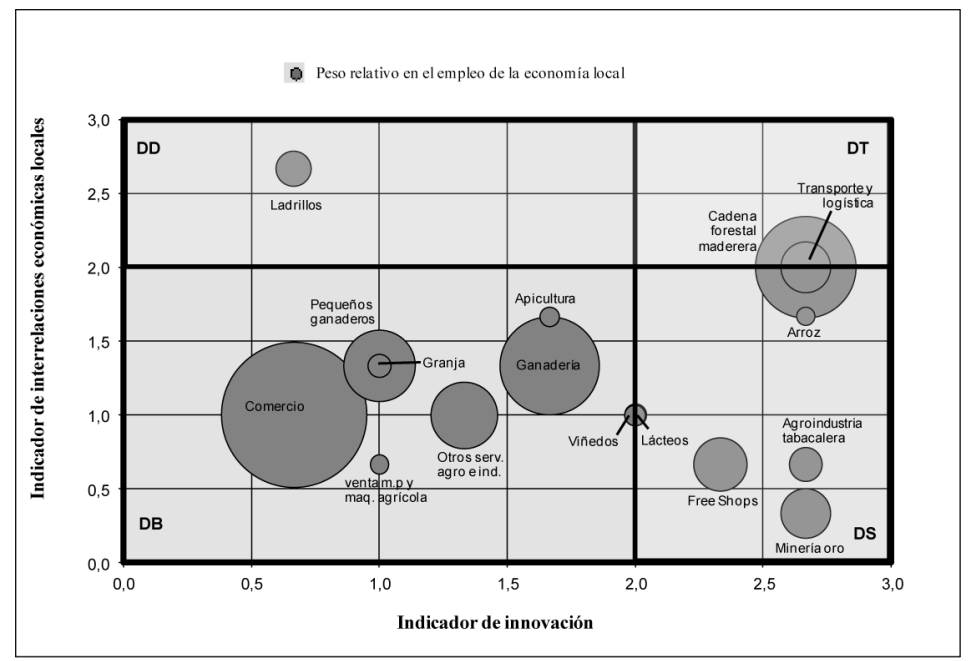

Fuente: elaboración propia.

\section{Cuadro 6}

\section{Indicadores $S$-T por categoría y peso en el empleo total}

\begin{tabular}{lccc}
\hline $\begin{array}{c}\text { Valores promedio de indicadores } \\
\text { según clasificación de sectores }\end{array}$ & $\begin{array}{c}\text { Indicador de } \\
\text { interrelaciones } \\
\text { locales }\end{array}$ & $\begin{array}{c}\text { Indicador de } \\
\text { innovación }\end{array}$ & $\begin{array}{c}\text { Peso (\%) en el } \\
\text { empleo total de } \\
\text { la economia }\end{array}$ \\
\hline Promedio DT (DS)* & 2 & 2,7 & $10.3 \%$ \\
Promedio DS & 0,6 & 2,5 & $6.2 \%$ \\
Promedio DD & 2,7 & 0,7 & $1.0 \%$ \\
Promedio DB & 1,1 & 1 & $33.7 \%$ \\
Promedio ponderado para el total & 1,2 & 1,4 & $51.2 \%$ \\
de sectores estudiados* & & & \\
\hline
\end{tabular}

* La cadena forestal maderera, transporte y logística que están situados en el límite entre el cuadrante DT y DS.

** Promedio ponderado por el peso en el empleo total.

Fuente: elaboración propia.

El análisis arroja que 49\% del empleo total de la economía corresponde a sectores seguidores (que acompañan la dinámica general del resto de sectores, que fueron los estudiados), $34 \%$ del empleo total se vincula con sectores de DB, mientras que sólo 16\% del empleo refiere a actividades con cierto dinamismo y capacidad innovadora, que si se acota a los sec- 
Figura IV

\section{Representación gráfica del análisis S-T para Rivera por grandes sectores}

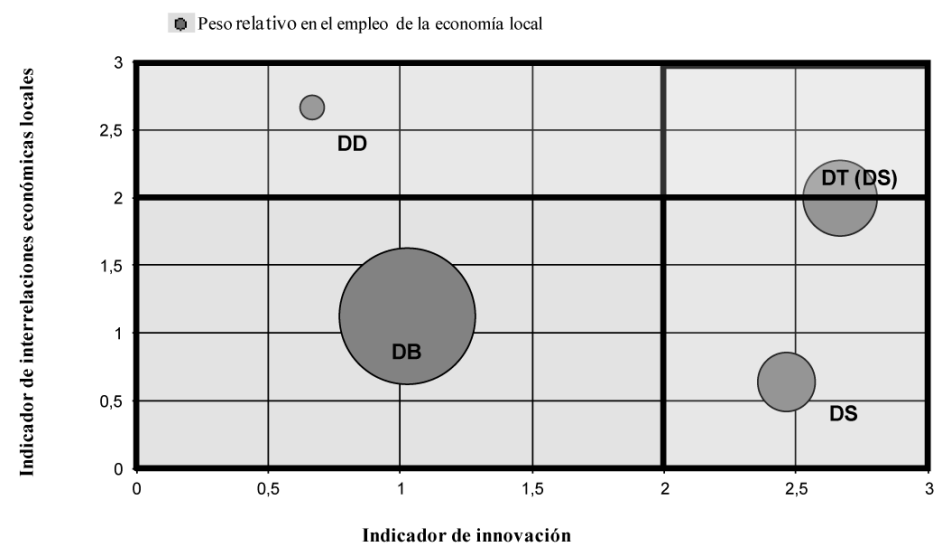

Fuente: elaboración propia.

tores que se asocian con la tipología DT pasa a ser 10\%. A partir de esto se puede reafirmar la idea de que la economía de Rivera refleja, en general, un conjunto de compartimentos estancos y de bajo dinamismo innovador, con algunos sectores que se muestran competitivos e innovadores, pero pocos de ellos con relacionamiento importante con el resto de la economía local.

En ese marco general, desfavorable para el desarrollo local, el análisis S-T permite identificar cuáles son los sectores con mayor potencialidad real para avanzar hacia funcionamientos más articulados localmente y que, a la vez, sean competitivos. Es el caso de la cadena forestal maderera y el sector de transporte y logística, actividades competitivas a nivel nacional e internacional que presentan vinculaciones importantes con el medio local.

Esto se refleja sobre todo en los subindicadores de relaciones con proveedores locales y acuerdos entre empresas, no es muy bueno el desempeño en cuanto a la participación en organizaciones locales (cuadro $2 \mathrm{~A}$ del anexo). Por ejemplo, si se avanza en el agregado de valor en la cadena forestal-maderera (al pasar de producir tablas y tableros básicos a incorporar mayores terminaciones o producir partes de muebles o casas de madera), y esto se realiza recurriendo a mayores relaciones económicas locales (proveedores y servicios), se podría generar una trayectoria de desarrollo territorial que diera lugar, incluso, al surgimiento de nuevos 
sectores vinculados a ese desarrollo. ${ }^{9}$ Por otra parte, las demandas que se podrían originar por un mayor desarrollo de los sectores maderero y logístico también podrían repercutir en una mejora de las otras actividades, que podrían aprovecharse de una mejor oferta local de servicios.

A partir de la caracterización de la economía local también es necesario analizar de qué forma se podría apoyar la generación de procesos de desarrollo local desde el desarrollo sectorial que ya existe. Este puede ser el caso de los free shops que, salvo el empleo directo que generan, no desarrollan mayores vínculos con la economía local. ${ }^{10}$ Por otro lado, tampoco hay en el territorio empresas que puedan identificarse como agentes promotores de turismo y, como se vio, el comercio y servicios de hotelería y restaurantes tienen condiciones de DB. Por lo tanto, existe aquí una línea de trabajo desafiante para articular actividades locales que hoy son de bajo dinamismo con actividades que sí son dinámicas y competitivas.

En este caso se requeriría lograr acuerdos y compromisos creíbles entre comercios locales, free shops, restaurantes, emprendedores, gobierno local, transporte de pasajeros y actores externos al territorio vinculados a la actividad turística. Al momento de escribir este artículo comienza a funcionar un hotel cuatro estrellas en Rivera, cuyo principal atractivo es un casino. Esto mejora una oferta hotelera que no contaba con un servicio de ese nivel. Por lo tanto, esto se ve con optimismo por la población local. Sin embargo, también puede ser un factor que refuerce las características actuales de la economía local, es decir, la presencia de algunos grandes emprendimientos dinámicos pero desconectados del resto de la economía local.

\section{Conclusiones}

La aplicación del análisis propuesto al caso de Rivera pretende ser útil para realizar diagnósticos económicos locales adecuados y pertinentes en cuanto a plazos y costos. Permite interpretar la dinámica económica local tanto desde una visión de conjunto sobre las restricciones y oportunidades para generar procesos de innovación con articulación territorial, así como desde una mirada focalizada por sector de actividad.

En particular, en las economías locales interiores es más probable que las oportunidades de crecimiento económico se asocien más frecuente-

\footnotetext{
${ }^{9}$ Esto es planteado también en ART-pnud (2008a, 2008b) y Rodríguez-Miranda (2010a, 2010b).

${ }^{10}$ Esto ya es señalado en ART-pNud (2008b) y Rodríguez-Miranda (2010a). Se trata de comercios en un régimen de tiendas de frontera (cuadro 5) que importan mercadería dirigida a un público de alto poder adquisitivo de ciudades brasileńas quienes hacen un turismo de compra de muy baja permanencia (sólo algunas horas) y solucionan sus requerimientos de insumos y servicios con proveedores externos (en Montevideo), al tiempo que tampoco desarrollan acuerdos con el comercio, restaurantes y hotelería local.
} 
mente a un desarrollo de tipo sectorial antes que territorial. Este modo de desarrollo, con desconexión del resto del tejido productivo, tiene una limitada capacidad real de transformar la economía local en clave de desarrollo territorial.

De esta forma se complejiza el problema que tradicionalmente se plantea para las regiones interiores en términos de cómo captar o generar sectores dinámicos. El verdadero dilema reside en cómo crecer en dinamismo sectorial de manera que los actores económicos locales puedan participar de ese proceso en forma más o menos relevante, lo que debería reflejarse en la conformación de un tejido de relaciones económicas locales más denso. En este sentido, el análisis $S$-T permite diagnosticar cuál es la situación de la economía local e identificar las potencialidades y restricciones sectoriales para poder promover un proceso de desarrollo territorial. La figura $\mathrm{v}$ muestra posibles trayectorias hacia una situación de DT.

Figura $\mathbf{v}$

Trayectorias hacia el desarrollo territorial

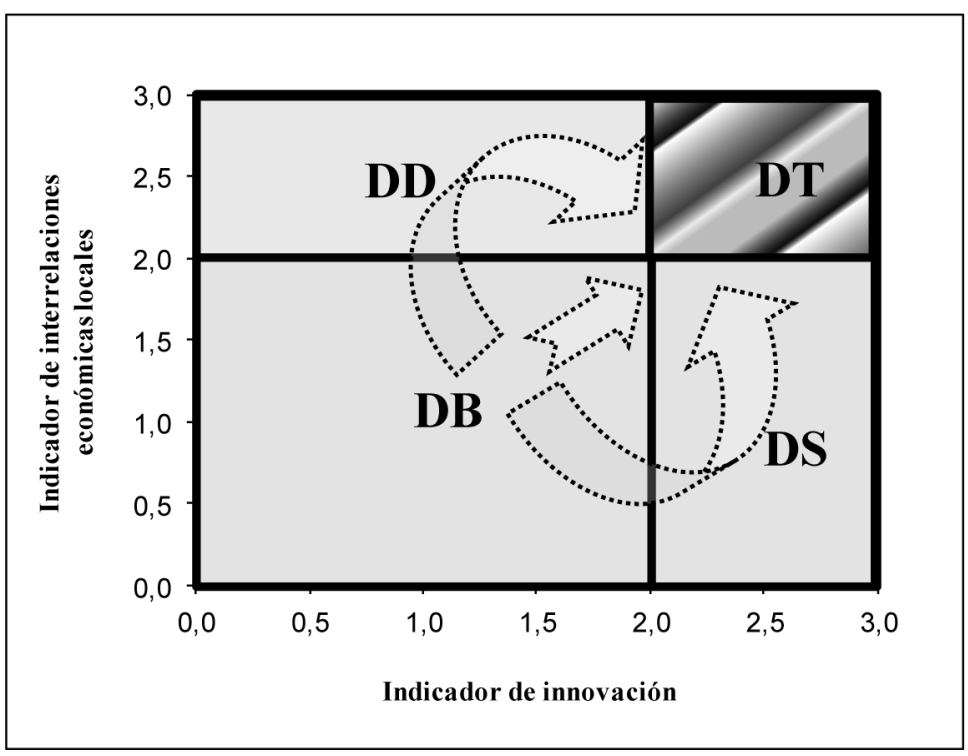

Fuente: elaboración propia.

Seguramente el camino hacia el desarrollo territorial sea sinuoso, de idas y vueltas, como todo proceso de aprendizaje. Si consideramos que el punto de partida es un territorio de DB, en forma simplificada, se pueden identificar tres trayectorias. Una refiere la generación de un impulso de cambio por el lado de la competitividad, lo que generaría capacidad 
de innovación en el territorio sobre la base de un desarrollo sectorial. Esto puede asociarse, por ejemplo, a una estrategia de captar inversiones externas o la promoción de grandes emprendimientos; en este tipo de economías, probablemente esas actividades refieran agroindustrias y sectores basados en recursos naturales. El desafío está en identificar cómo vincular esos sectores con proveedores, servicios y otras actividades económicas locales.

Otra trayectoria posible es el fortalecimiento de las relaciones económicas locales en aquellos emprendimientos de baja capacidad innovadora $y$, por ende, poco competitivos. Se trata de crear colectivos representativos de intereses locales y capaces de articular proyectos comunes, los que con apoyo desde las políticas públicas puedan comenzar a transitar hacia desarrollos competitivos sobre la base de generación de procesos de cambio (innovación) ajustados a las posibilidades reales del territorio. Sin embargo, puede ser necesario considerar que algunos sectores requieren períodos de transición bajo formas de desarrollo defensivo.

Por último, se puede intentar transitar por la combinación de las dos dimensiones analizadas: innovación y articulación local. Por ejemplo, al mismo tiempo que se impulsan sectores dinámicos, incluso con inversiones externas al territorio, se pueden articular relaciones económicas locales en torno a los mismos. Una de las políticas que pueden favorecer estos procesos refiere la instrumentación de programas de desarrollo de proveedores locales. Otras acciones, por ejemplo, pueden referirse a planificar e instrumentar la preparación de capital humano local en función de la identificación previa de las demandas futuras que generarán dichas actividades dinámicas.

Todas estas posibles estrategias planteadas, como señala Alburquerque (2013), requieren una lectura a profundidad del territorio y de la participación de los actores locales en el diagnóstico y diseño de las políticas. La responsabilidad en la convocatoria de dichos actores, la apertura de espacios de reflexión y discusión, así como la articulación de ese proceso, debe ser una competencia principal de los gobiernos locales. En definitiva, cada territorio deberá discutir, consensuar y negociar hacia dentro y hacia afuera una estrategia propia de desarrollo. 


\section{Anexo}

\section{Cuadro 1A}

Antecedentes y estudios previos para Rivera

\begin{tabular}{|c|c|c|}
\hline Fuente & Descripción & Año \\
\hline $\begin{array}{l}\text { Rodríguez- } \\
\text { Miranda, A. }\end{array}$ & $\begin{array}{l}\text { "Desarrollo económico en el noreste de Uruguay: una } \\
\text { aproximación a partir de la organización productiva y la } \\
\text { articulación rural-urbana", Tesis de doctorado en Inte- } \\
\text { gración y Desarrollo Económico de la Universidad Au- } \\
\text { tónoma de Madrid (Espańa). }\end{array}$ & 2010 \\
\hline $\begin{array}{l}\text { ART Uruguay } \\
\text { (PNUD) }\end{array}$ & $\begin{array}{l}\text { "Cuadernos para el desarrollo local. Diagnóstico econó- } \\
\text { mico local. Rivera", Programa de Desarrollo Local ART } \\
\text { Uruguay, serie Recursos económicos y sociales para el } \\
\text { desarrollo social, PNUD, Montevideo. }\end{array}$ & 2008 \\
\hline $\begin{array}{l}\text { ART Uruguay } \\
\text { (PNUD) }\end{array}$ & $\begin{array}{l}\text { "Agencia de Desarrollo Local de Rivera. Apoyo a la defi- } \\
\text { nición de acciones para desarrollar cadenas de valor te- } \\
\text { rritorial", Intendencia de Rivera, Oficina de Planeamien- } \\
\text { to y Presupuesto, ART Uruguay, PNUD, Montevideo. }\end{array}$ & 2008 \\
\hline Prodenor & $\begin{array}{l}\text { Informes y documentos del Proyecto de Desarrollo Social } \\
\text { de las Zonas Rurales más pobres del norte de Uruguay } \\
\text { (Prodenor). En línea en www.prodenor.com }\end{array}$ & $\begin{array}{c}2004 \mathrm{a} \\
2007\end{array}$ \\
\hline Claeh & $\begin{array}{l}\text { Desarrollo rural sostenible en el noreste de Uruguay. Siste- } \\
\text { matización de experiencias, Claeh, Montevideo. }\end{array}$ & 2005 \\
\hline UdelaR - FCEA & $\begin{array}{l}\text { La economía de Rivera en los noventa, serie La economía } \\
\text { uruguaya en los noventa. Análisis y perspectiva de largo } \\
\text { plazo, Convenio UTE-Universidad de la República, Ed. } \\
\text { Artes Gráficas S.A., Montevideo. }\end{array}$ & 1998 \\
\hline Claeh & $\begin{array}{l}\text { Un potencial de desarrollo que aún es promesa: el caso de } \\
\text { Tranqueras, Claeh, Montevideo. No publicado. }\end{array}$ & 1993 \\
\hline
\end{tabular}

Fuente: elaboración propia. 


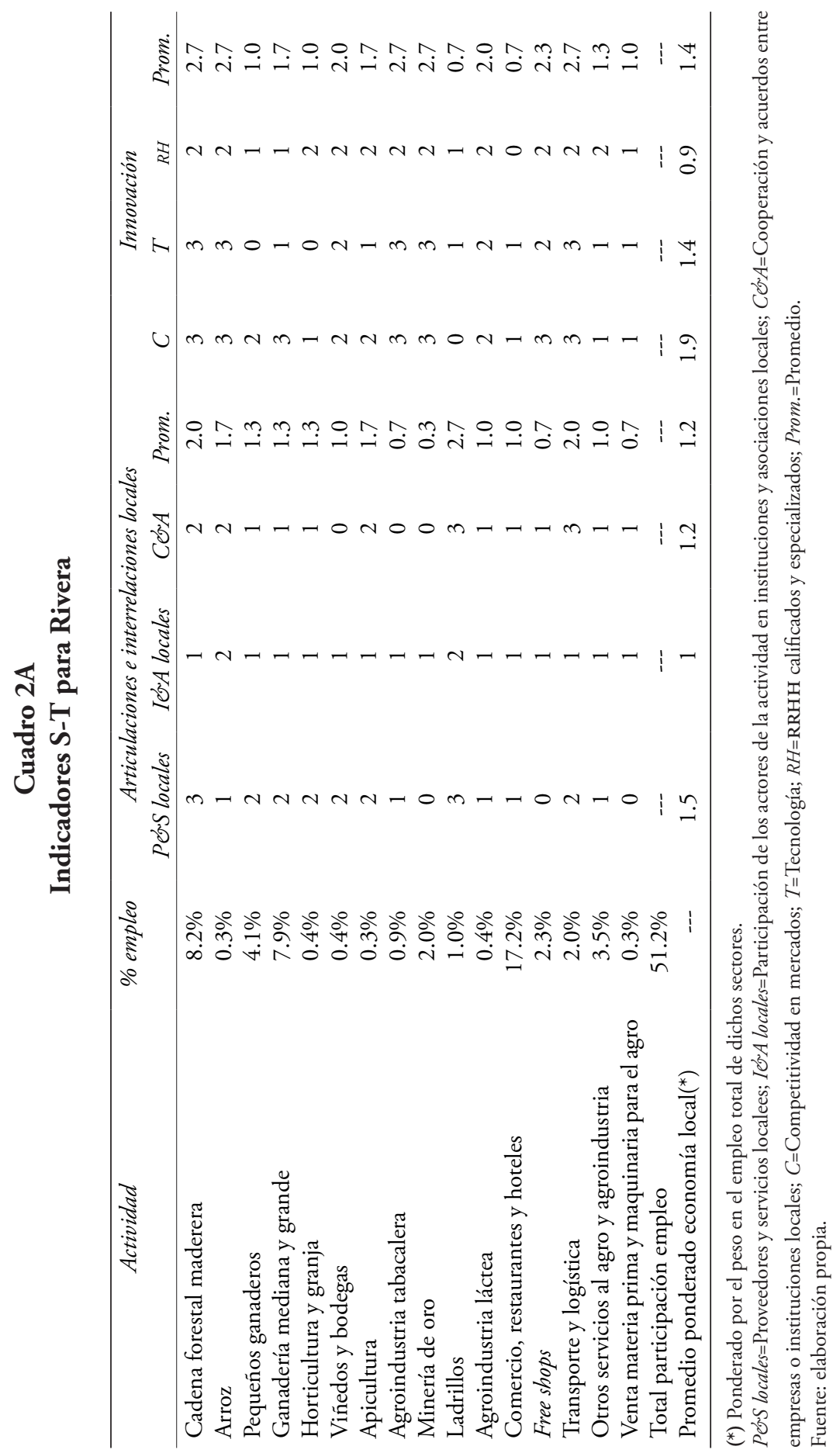




\section{Cuadro 3A}

\section{Entrevistas realizadas en el caso de Rivera}

\begin{tabular}{lc}
\hline \multicolumn{1}{c}{ Categoría de los entrevistados } & Entrevistas \\
\hline Referentes de agroindustrias y actividades manufactureras & 6 \\
Referentes de comercio, logística y servicios a empresas & 4 \\
Asociaciones empresariales y organizaciones locales & 5 \\
Referente de institución de enseñanza técnica & 1 \\
Consultores externos de programas de cooperación internacional & 2 \\
Referentes locales en programas de cooperación internacional & 2 \\
Autoridades y técnicos del gobierno local & 3 \\
Total de entrevistados & 23 \\
\hline
\end{tabular}

Fuente: elaboración propia.

\section{Bibliografía}

Alburquerque, Francisco (2013), "Política regional y desarrollo territorial en América Latina y el Caribe”, ConectaDEL. Programa Regional de Formación para el Desarrollo Económico Local con Inclusión Social en América Latina y el Caribe, pp. 1-31, <http://www. conectadel.org/biblioteca/?did=259>, enero de 2014.

ART-pnud (Articulación de Redes Territoriales para el Desarrollo Humano Sostenible-Programa de las Naciones Unidas para el Desarrollo) (2008a), "Apoyo a la definición de acciones para desarrollar cadenas de valor territorial”, Programa de Desarrollo Local ART Uruguay-opp, Montevideo.

ART-pnud (Articulación de Redes Territoriales para el Desarrollo Humano Sostenible-Programa de las Naciones Unidas para el Desarrollo) (2008b), "Diagnóstico Económico Local de Rivera", Cuadernos para el Desarrollo Local,", Programa de Desarrollo Local ART Uruguay, Montevideo.

Aydalot, Philippe (1986), Milieux innovateurs en Europe, Gremi, Paris.

Bianchi, Patrizio y Sandrine Labory (2011), "Industrial policy after the crisis: the case of the Emilia-Romagna region in Italy", Policy Studies, 32 (4), Routledge Taylor \& Francis, London, pp. 429-445. 
Boisier, Sergio (1993), "Desarrollo regional endógeno en Chile. ¿Utopía o necesidad?", Ambiente y Desarrollo, IX (2), cIpma, Santiago de Chile, pp. 42-45.

Castells, Manuel (2000), La sociedad red, Alianza, Madrid.

Cimoli, Mario (ed.) (2005), Heterogeneidad estructural, asimetrías tecnológicas y crecimiento de América Latina, Naciones Unidas, Santiago de Chile.

Conventz, Sven, Ben Derudder, Alain Thierstein y Frank Witlox (eds.) (2014), Hub cities in the knowledge economy. Seaports, airports, brainports, Ashgate Publishing Ltd, Burlington.

Diez, José Ignacio y Verna-Etcheber, Roberto (2012), “¿Puede construirse distritos industriales en territorios periféricos? Análisis del caso DIMSUR en la Provincia de Buenos Aires (Argentina)", Revista lider, 20, Universidad de los Lagos, Santiago de Chile, pp. 77-108.

Fachinelli, Ana Cristina, Francisco Javier Carrillo y Anelise D’Arisbo (2014), "Capital system, creative economy and knowledge city transformation: insights from Bento Gonçalves, Brazil", Expert Systems with Applications, 41 (12), Elsevier, Maryland, pp. 5614-5624.

Ferreira, Fabiana, Marcos G. Gomes y Virgínia Motta (2012), “Uma reflexão sobre as relações de parceria nos APLs de Confecções do Agreste Pernambucano como elemento disseminador da inovação em redes interorganizacionais", Revista de Administração Mackenzie, 13 (4), Centro de Ciências Sociais e Aplicadas-Programa de Pós-Graduação em Administração da Universidade Presbiteriana Mackenzie, São Paulo, pp. 206-235.

Fujita, Masahisa (1992), "Monopolistic competition and urban systems", European Economic Review 37 (2-3), North Holland Publishing Company, North Holland, pp. 308-315.

Hatzichronoglu, Thomas (1997), "Revision of the high-technology. Sector and product classification", Science, Technology and Industry working papers, 1997/02, OECD, Publishing, Paris, pp. 1-25. 
Harvey, David (1990), The condition of postmodernity. An enquiry into the origins of cultural change, Blackwell Publishers, CambridgeOxford.

Hidalgo, C. A., B. Klinger, L. Barabási, y R. Hausmann (2007), "The product space conditions the development of nations", Science, 317 (5837), American Association for the Advancement of Science, New York, pp. 482-487.

Hsieh, Hung-Nien, Tai-Shan Hu, Ping-Ching Chia, Chieh-Chung Liu (2014), "Knowledge patterns and spatial dynamics of industrial districts in knowledge cities: Hsinchu, Taiwan", Expert Systems with Applications, 41 (12), Elsevier, Maryland, pp. 5587-5596.

IBGE (Instituto Brasilero de Geografía y Estadística): <http://www.ibge. gov.br/>, 1 de marzo de 2012.

INE (Instituto Nacional de Estadística) (2004), Censo fase-I, INE, <http:// www.ine.gub.uy/fase1 new/divulgacion_definitivos.asp>.

Jacobs, J. (1969), The economy of cities, Random House, Londres.

Lall, Sanjaya (2000), "The technological structure and performance of developing country manufactured exports, 1985-98”, Oxford Development Studies, 28 (3), Taylor \& Francis Journals, Oxford, pp. 337-369.

Jofre-Monseny, Jordy, Raquel Marín-López y Elisabet Viladecans-Marsal (2014) "The determinants of localization and urbanization economies: evidence from the location of new firms in Spain", Journal of Regional Science, 54 (2), Wiley, Sioux Falls, pp. 313-337.

Keilbach, Max (2000), Spatial knowledge spillovers and the dynamics of agglomeration and regional growth, Physica Verlag, Heidelberg.

Krugman, Paul (1991) "Increasing returns and economic geography", Journal of Political Economy, 99 (3), University of Chicago Press, Chicago, pp. 483-499.

Krugman, Paul (1995), Development, geography, and economic theory, MIT Press, Cambridge. 
Maillat, Dennis (1995), "Les milieux innovateurs", Sciences Humaines, 8, Jean-François Dortier, Auxerre, pp. 41-42.

Méndez, R. (2000), "Procesos de innovación en el territorio: los espacios innovadores", en José A. Alonso y Ricardo Méndez, Innovación, pequeña empresa y desarrollo local en España, Civitas, Madrid.

Nelson, Richard y Sydney Winter (1974), "Neoclassic versus evolutionary theories of economic growth", Economic Journal, 84 (336), Wiley, New Jersey, pp. 886-905.

opp (Oficina de Planeamiento y Presupuesto) (2009), "Estrategia Uruguay III siglo. Aspectos productivos. Documento para discusión”, OPPPresidencia de la República, Montevideo.

Porcile, Gabriel, Marcio Holland, Mario Cimoli y Luciana Rosas (2006), "Especialización, tecnología y crecimiento en el modelo Ricardiano", Nova Economia, 16 (3), Departamento de Ciências Econômicas de Universidade Federal de Minas Gerais, Belo Horizonte, pp. 483-506.

Ramírez, Juan Carlos, Horacio Osorio, Rafael Isidro Parra-Peña (2007), "Escalafón de la competitividad de los departamentos en Colombia", Estudios y perspectivas, 16, Naciones Unidas, Santiago de Chile, pp. 1-139.

Rodríguez-Miranda, Adrián (2006), 'Desarrollo económico territorial endógeno. Teoría y aplicación al caso uruguayo", Serie Documentos de Trabajo, DT 2/2006, Instituto de Economía-FCEA-Universidad de la República, Montevideo, pp. 1-72.

Rodríguez-Miranda, Adrián (2010), “Desarrollo económico en el noreste de Uruguay: una aproximación a partir de la organización productiva y la articulación rural-urbana", tesis de grado doctoral, Universidad Autónoma de Madrid, Madrid.

Saviotti, Pier Paolo y Andreas Pyka (2004), "Economic development, variety and employment”, Revue économique, 55 (6), Presses de Sciences Po, Paris, pp. 1023-1049.

Schumpeter, Joseph A. (1934), The theory of economics development, Harvard University Press, Cambridge. 
Storper, M. (1988), "Las economías regionales como activos relacionales", Economiaz, 41, Gobierno Vasco, Vitoria-Gasteiz, pp.10-45.

Vázquez-Barquero, Antonio (2002a), Endogenous development, Routledge, London.

Vázquez-Barquero, Antonio (2002b), “Crecimiento endógeno o desarrollo endógeno", en Giacomo Becattini, María Teresa Costa y Joan Trullén (eds.), Desarrollo local: teorías y estrategias, Civitas, Madrid, pp. 83-104.

Vázquez-Barquero, Antonio (2005), Las nuevas fuerzas del desarrollo, Antoni Bosch, Madrid.

Veltz, Pierre (1999), Mundialización, ciudades y territorios: la economía del archipiélago, Editorial Ariel Económica, Barcelona.

Vogiatzoglou, Klimis y Theodore Tsekeris (2013), "Spatial agglomeration of manufacturing in Greece: sectoral patterns and determinants", European Planning Studies, 21 (12), Routledge Taylor \& Francis, Abingdon, pp. 1853-1872.

Recibido: 27 de abril de 2012. Reenviado: 12 de julio de 2013. Aceptado: 22 de abril de 2014.

Adrián Rodríguez-Miranda. Doctor en desarrollo económico e integración por la Universidad Autónoma de Madrid, Espańa; licenciado y magíster en economía por la Universidad de la República de Uruguay. Actualmente es coordinador del Grupo de Investigación en Desarrollo Local y Regional del Instituto de Economía de la Facultad de Ciencias Económicas y Administración de la Universidad de la República. Es integrante del Sistema Nacional de Investigadores de Uruguay; coordinador de la Red Temática de Desarrollo y co-coordinador del Núcleo Interdisciplinario de Estudios del Desarrollo Territorial de la Universidad de la República; coordinador de la Red Iberoamericana de Estudios del Desarrollo (RIED). Miembro de la Red de Desarrollo Territorial para América Latina y el Caribe (Dete-Alc). Entre sus publicaciones destacan: "Desarrollo económico y disparidades territoriales en Uruguay", Cuadernos de Desarrollo Humano, 3, PNUd, pp. 1-92 (2014); "The case of Canelones (Uruguay) with the government of the Canary Islands and the 
deputation of Barcelona (Spain)", en G. Gorzelak et al., European territorial co-operation as a factor of growth, jobs and quality of life, Espon and Euroreg, Luxembourg, pp. 566-634, (2012); "Desarrollo territorial rural y articulación rural-urbana en Uruguay”, en Luis Enrique Gutiérrez y Myrna Limas (coords.), Nuevos enfoques del desarrollo. Una mirada desde las regiones, Universidad Autónoma de Ciudad Juárez, Ciudad Juárez, (2011); en coautoría, Desarrollo de capacidades para emprender. Manual para equipos técnicos e instituciones que apoyan microemprendimientos, Editorial Fin de Siglo, Montevideo (2011); "La frontera Uruguay-Brasil y el desarrollo local”, Nóesis, 19 (37), Universidad Autónoma de Ciudad Juárez, Ciudad Juárez, pp. 286-327 (2010); "Desarrollo económico en el noreste de Uruguay: articulación rural-urbana y organización productiva”, Serie documentos de trabajo, 3 (10), Universidad de la República, Uruguay, pp. 1-37 (2010). 